\title{
Right Frontoinsular Cortex and Subcortical Activity to Infant Cry Is Associated with Maternal Mental State Talk
}

\author{
DAlison E. Hipwell, ${ }^{1,2}$ Chaohui Guo, ${ }^{1}$ Mary L. Phillips, ${ }^{1,2}$-James E. Swain, ${ }^{3,4}$ and Eydie L. Moses-Kolko ${ }^{1}$ \\ ${ }^{1}$ Department of Psychiatry, Western Psychiatric Institute and Clinic, University of Pittsburgh School of Medicine, Pittsburgh, Pennsylvania 15213, \\ ${ }^{2}$ Department of Psychology, University of Pittsburgh, Pittsburgh, Pennsylvania 15213, ${ }^{3}$ Department of Psychiatry, University of Michigan, Ann Arbor, \\ Michigan 48109 and ${ }^{4}$ Child Study Center, Yale University, New Haven, Connecticut 06520
}

The study objective was to examine neural correlates of a specific component of human caregiving: maternal mental state talk, reflecting a mother's proclivity to attribute mental states and intentionality to her infant. Using a potent, ecologically relevant stimulus of infant cry during fMRI, we tested hypotheses that postpartum neural response to the cry of "own" versus a standard "other" infant in the right frontoinsular cortex (RFIC) and subcortical limbic network would be associated with independent observations of maternal mental state talk. The sample comprised 76 urban-living, low socioeconomic mothers (82\% African American) and their 4-month-old infants. Before the fMRI scan, mothers were filmed in face-to-face interaction with their infant, and maternal behaviors were coded by trained researchers unaware of all other information about the participants. The results showed higher functional activity in the RFIC to own versus other infant cry at the group level. In addition, RFIC and bilateral subcortical neural activity (e.g., thalamus, amygdala, hippocampus, putamen) was associated positively with maternal mental state talk but not with more global aspects of observed caregiving. These findings held when accounting for perceptual and contextual covariates, such as maternal felt distress, urge to help, depression severity, and recognition of own infant cry. Our results highlight the need to focus on specific components of caregiving to advance understanding of the maternal brain. Future work will examine the predictive utility of this neural marker for mother-child function.

Key words: affective-perceptual empathy; mental state talk; right frontoinsular cortex (RFIC); subcortical limbic region

\section{Significance Statement}

The current study advances extant literature examining the neural underpinning of early parenting behavior. The findings highlight the special functional importance of the right frontoinsular cortex-thalamic-limbic network in a mother's proclivity to engage in mental state talk with her preverbal infant, a circumscribed aspect of maternal caregiving purported to be a prerequisite of sensitive and responsive caregiving. These associations existed specifically for maternal mentalizing behavior and were not evident for more generic aspects of caregiving in this urban sample of 76 postpartum mothers. Finally, the findings were robust even when controlling for potential demographic, perceptual, and contextual confounds, supporting the notion that these regions constitute an innate, specialized maternal mentalizing network.

\section{Introduction}

The importance of early caregiving quality for subsequent child functioning is well recognized (Lorber and Egeland, 2009). Social-cognitive and attachment theories converge on the significance of one aspect of the complex parenting system, contending that a mother's capacity to "read," understand, and attribute

\footnotetext{
Received April 3, 2015; revised July 2, 2015; accepted Aug. 6, 2015.

Author contributions: A.E.H., M.L.P., J.E.S., and E.L.M.-K. designed research; A.E.H. and E.L.M.-K. performed research; A.E.H., C.G., and E.L.M.-K. analyzed data; A.E.H., C.G., M.L.P., J.E.S., and E.L.M.-K. wrote the paper.

This research was supported by National Institute of Child Health and Human Development Grant HD067185 (A.E.H. and E.L.M.-K.). We are grateful to Amanda Allen, Samantha McClelland, Natalie Merrick, Laura Rottingen, Cathy Sterling, and Danielle Verble for their tremendous efforts in data collection, Carlos Zevallos and Ricki Stiffler for assistance with data management, and Elena Paul and Joe Beeney for expert observational coding. We thank all of the research participants and their families for their time dedicated to this study.
}

mental states (e.g., desires, intentions, and beliefs) to her infant is a prerequisite for sensitive and responsive caregiving and provides a critical foundation for positive child development (Meins and Fernyhough, 1999; Sharp and Fonagy, 2008). Behavioral studies have provided consistent empirical support for links between declarative indices of maternal mentalizing and sensitivity in mother-infant interactions (Laranjo et al., 2008; Meins et al., 2012), as well as subsequent social-cognitive abilities in the child,

\footnotetext{
The authors declare no competing financial interests.
}

Correspondence should be addressed to Drs. Alison E. Hipwell and Chaohui Guo, Western Psychiatric Institute and Clinic, University of Pittsburgh Medical Center, 3811 0'Hara Street, Pittsburgh, PA 15213 E-mail: hipwae@upmc.edu and guoc2@upmc.edu.

DOI:10.1523/JNEUROSCI.1286-15.2015

Copyright $\odot 2015$ the authors $\quad 0270-6474 / 15 / 3512725-08 \$ 15.00 / 0$ 
including perspective taking (Taumoepeau and Ruffman, 2008), emotion understanding (Doan and Wang, 2010), and empathic awareness (Meins and Fernyhough, 1999). Conversely, deficits in maternal mentalizing are associated with mother-child conflict (Meins et al., 2003), dysfunctional parenting, and maltreatment (Mammen et al., 2003; Berlin et al., 2013). Clinical studies have also shown that mentalization-based interventions can improve early parenting quality for some mothers (Cooper et al., 2005; Sadler et al., 2013). Although these data support the behavioral and clinical utility of maternal mentalizing, little is known about the underlying neural circuitry. Filling this gap could help to hone targets for prevention and to specify more individualized and effective treatments.

Among nonparents, extensive research on the neural mechanisms of perceptual affective empathy induced by imitating others' emotions (Abu-Akel, 2003; Fan et al., 2011) has highlighted the functional importance of the right frontoinsular (RFIC) and rolandic operculum (ROC) cortices in the neural operations of action representation. These areas facilitate empathic responses and the modulation of one's own emotional experience, which enables understanding of others (Carr et al., 2005). Importantly, these areas overlap those in the macaque brain that possess mirror neurons, defined as cells that fire both during goal-directed action and also when observing that action performed by others (Iacoboni and Dapretto, 2006). Analogous regions in humans thought to possess mirror neurons that mimic the brain response of others' actions and intentions (Molenberghs et al., 2012) are related to high levels of synchrony within mother-child dyads (Rizzolatti and Fabbri-Destro, 2008) and become activated when mothers are presented with infant stimuli (Swain et al., 2014). Recent work showed that greater RFIC activation in response to child cry stimuli was associated with higher levels of observed maternal sensitivity (Musser et al., 2012); however, research examining specific associations between RFIC activity and maternal mentalizing behavior is lacking.

A parallel body of animal research has established that functional integrity of a widespread subcortical network, including the thalamus, amygdala, hippocampus, caudate, hypothalamus, and periaqueductal gray (PAG), is necessary for intact maternal rodent behaviors, such as pup retrieval, nest building, and suckling (Swain et al., 2007). A growing number of studies confirm the involvement of this subcortical network in human maternal caregiving by demonstrating greater functional activity in these regions when mothers are exposed to emotionally salient stimuli of their own versus an unfamiliar infant (Swain et al., 2008; Barrett et al., 2012; Strathearn and Kim, 2013). Infant cry sounds, in particular, have uniquely salient signaling properties that drive maternal response (Soltis, 2004; Swain et al., 2004). Furthermore, important perceptual and contextual covariates of subcortical neural activity to infant cry sounds (e.g., felt distress, urge to respond, and postpartum mood) are emerging in several studies, which warrant elaboration in larger samples.

Drawing on a relatively large sample of first-time mothers, we hypothesized that two key brain regions, the RFIC and the subcortical amygdala-thalamic-hypothalamic lower mammalian maternal network, would show greater functional involvement in response to "own" versus "other" infant cry in the postpartum period. We expected that increased neural activity in these regions would be more closely associated with maternal mental state talk than with more generic aspects of caregiving and that these relationships would remain after controlling for potential demographic, perceptual, and contextual confounds.

\section{Materials and Methods}

The sample comprised a subset of young adult participants (18-22 years) of the Pittsburgh Girls Study (PGS) who had become a mother for the first time. The PGS is a longitudinal population-based study of the development of psychopathology beginning in childhood (girls originally aged 5- 8 years). The PGS sample $(n=2450)$ was formed after enumeration of 103,238 City of Pittsburgh households in 1999-2000. In this process, all households in 23 low-income neighborhoods (using 1990 census data on poverty) and $50 \%$ of households in the remaining 66 city neighborhoods were enumerated (for details, see Hipwell et al., 2002; Keenan et al., 2010). To date, the sample has been followed annually for 15 years (participants currently aged 19-22 years), with a mean retention rate of $90.1 \%$.

To be eligible for the neuroimaging assessment, PGS participants needed to be aged $\geq 18$ years, with a healthy, first-born, singleton child younger than 6 months, for whom they provided at least $2 \mathrm{~h}$ of care daily $(n=155)$. Young mothers were then excluded if they were pregnant again at the time of the scan $(n=5)$, met diagnostic criteria for bipolar illness $(n=5)$ or cannabis abuse $(n=8)$, had medical or neurological illnesses likely to affect cerebral physiology or anatomy $(n=6)$, used psychotropic medication daily $(n=3)$, had metal present in their body $(n=4)$, were claustrophobic and unable to enter the scanner $(n=1)$, had an IQ $<65(n=2)$, or were living out of state $(n=5)$. In addition to these $39(25 \%)$ excluded participants, eight scan-eligible women refused participation (5\%), and 13 were lost to follow-up (8\%), resulting in a sample of 95 completed scans.

Subjects provided written informed consent as approved by the University of Pittsburgh Institutional Review Board. At 12 weeks postpartum $($ mean $=12.7 \pm 3.9)$, participants were visited at home to obtain an audio recording of the infant's distressed cry when the infant was not in pain or hunger. Mothers were first asked for reliable methods to elicit a distressed cry, such as placing the infant in a car seat, on his/her tummy, or mother leaving the room. If these methods were unsuccessful, the researcher administered a set of physical manipulations (e.g., arm across body), consistent with a pediatric assessment of infant muscle tone and reflexes (Menkes et al., 2000), to elicit a distressed cry. The cry samples were edited with Adobe Audition (Syntrillium Software) to create standardized audio clips for use in the scanner. The standard other infant cry was recorded while an experienced pediatrician assessed infant reflexes using the Neonatal Intensive Care Unit Network Neurobehavioral Scale (Tronick et al., 2004) during piloting and staff training. A strong distress cry was elicited from an aversive stimulus (i.e., a cloth placed over the infant's face with nose pinched).

At $\sim 4$ months postpartum ( mean $=17.1 \pm 4.6)$, the mother visited the research suite with her infant to complete interview measures, to have observations of mother-infant interactions filmed, and to have an fMRI scan at the Magnetic Resonance Imaging Research Center, University of Pittsburgh.

Interview measures. Mothers reported on age, infant age, maternal race, years of education, and past year receipt of public assistance (e.g., Women, Infants, and Children program assistance, food stamps, and welfare), which was used as an index of household poverty. Severity of postpartum depression was assessed on the 10-item Edinburgh Postnatal Depression Scale (EPDS; Cox et al., 1987) with reports of depressed mood, anhedonia, guilt, anxiety, and suicidal ideation experienced in the past $7 \mathrm{~d}$ rated on four-point scales (0-3). An EPDS score above 12 indicates "probable" depression (Gibson et al., 2009). Mothers were considered to be breastfeeding if at least $80 \%$ of the infant's nutrition was delivered via breast milk. Handedness was determined with the Edinburgh Handedness Inventory (Oldfield, 1971). Cannabis use was assessed by self-report and by urine drug screen on the day of the scan.

Observed maternal mentalizing behavior and global ratings of caregiving. When the infant was alert and not distressed, each mother-infant dyad was filmed in face-to-face interaction during warm-up play when the mother was asked to talk to her infant "in any way she wanted to" without the use of toys, followed by an episode of toy play when the mother was asked to "help your child to get interested" in a specific toy. Infants were seated in a high chair in front of an angled mirror, and the interaction was 
filmed with a camcorder that captured a full view of both the mother's and the infant's faces.

Caregiving behaviors during the warm-up and toy-play episodes were coded by two independent observers using time-sampled global ratings. The trained coders were unaware of all other information about the mother-infant dyads, and ratings of behaviors in the warm-up session were also coded independently from ratings in the toy-play sessions. Maternal mental state talk was coded from verbatim transcriptions of maternal speech during the filmed session. Comments that attributed mental states, desires, intentionality, and agency to the infant (e.g., "Do you think that's funny?" or "Are you saying you want to go home?") were coded. The frequency of mental state talk was then rated on four-point scales ( 1 for no comments; 4 for five or more comments). Inter-rater reliability was determined from intraclass correlation coefficients (ICCs) calculated on a random selection of 25 mother-infant pairs (33\%), which revealed an ICC of 0.91 . This construct also showed moderate stability across the warm-up and toy-play sessions (ICC of $0.62, p \leq 0.001$ ), and so a mean score was calculated.

To determine neurobiological specificity to maternal mental state talk, five other dimensions of maternal behavior (hostility, intrusiveness, warmth, involvement, and sensitivity) were coded using rating scales adapted from the Early Parenting Coding System (Shaw et al., 1998). Ratings of hostility reflected maternal negative expressions, such as impatience, annoyance, critical comments, angry teasing, and sharp tone of voice. Intrusive behaviors included rough pulling and poking at the infant, lunging face or hands close to the infant's face, and loud or highpitched vocalizing. The maternal warmth dimension evaluated the amount of positive affect (e.g., smiling or laughter) expressed toward the child. Maternal involvement assessed the extent to which the mother attended to and attempted to engage with the infant, and maternal sensitivity measured the extent to which the mother responded promptly and appropriately to the infant's bids and emotional state. The dimensions were rated on four-point Likert scales that were behaviorally anchored for each scale and ranged from 1 (none/low/minimal) to 4 (a lot/highly). Inter-rater reliability was good as indicated by an ICC of 0.94 for hostility, 0.92 for intrusiveness, 0.84 for warmth, 0.72 for involvement, and 0.83 for maternal sensitivity. To reduce the number of outcome variables, the warm-up and toy-play ratings on each these five dimensions were entered into a principal components analysis with varimax rotation, which produced two components explaining $68.2 \%$ of the variance. The first component comprised maternal warmth and involvement (factor scores of 0.80 and 0.84 , respectively), which was labeled "positive involvement." The second component comprised hostility, intrusiveness, and (low) sensitivity (factor scores of 0.67, 0.91, and -0.63 , respectively) and was labeled "negative insensitivity."

fMRI infant cry paradigm. Before scanning, participants completed a practice paradigm outside the scanner (listening to nature sounds from the acoustic library of the International Affective Picture System, http:// csea.phhp.ufl.edu/media/iadsmessage.html) to ensure that they understood the task response format. While positioned in a supine orientation in the MRI scanner, mothers then listened to four, $36 \mathrm{~s}$ sound blocks (comprising three $11 \mathrm{~s}$ epochs separated by $1 \mathrm{~s}$ breaks) each of own infant cry, a standard other infant cry, and a garbled sound consisting of randomly ordered $0.4 \mathrm{~s}$ clips of own and standard cry (Sander et al., 2007). The three stimulus types were presented in a pseudorandom order across the 12 blocks. In the current analysis, we focus on differences between own and other infant cry conditions, the most relevant contrast for identifying regions related to familiarity of human sounds that drive maternal behavior. Four $24 \mathrm{~s}$ rest periods were incorporated at the beginning, middle, and end of the task. Immediately after each $36 \mathrm{~s}$ block of cry stimuli, mothers were asked to rate their feelings of distress induced by the cry sounds and their urge to help the infant on three-point scales (2 for low, 3 for medium, and 4 for high) with a glove on their right hand (Psychology Software Tools). Subjects had $3 \mathrm{~s}$ to respond to each question (Fig. 1). Task performance response and reaction times were recorded using E-Prime software on a synchronized personal computer.

After the scan procedure, participants listened to the same infant cry stimuli (three $11 \mathrm{~s}$ own infant cries and three $11 \mathrm{~s}$ other infant cries) for a second time and rated their confidence in the identity of the infant ( 1 for

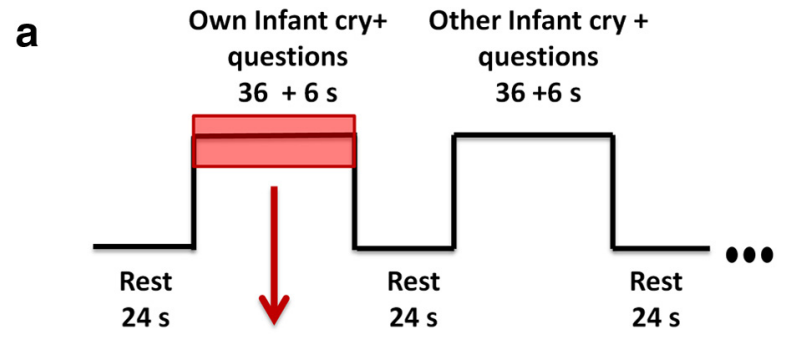

b

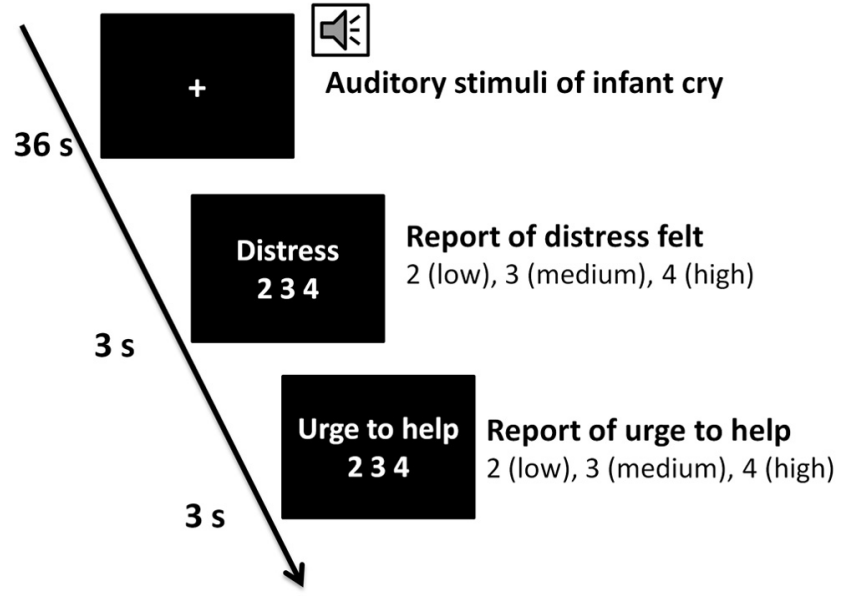

Figure 1. Task (a) and an example of a trial $(\boldsymbol{b})$.

Table 1. Sample characteristics $(n=76)$

\begin{tabular}{lccc}
\hline & $\mathrm{n}(\%)$ & \multicolumn{1}{c}{ Mean \pm SD } & \multicolumn{1}{c}{ Range } \\
\hline $\begin{array}{l}\text { Maternal age (years) } \\
\text { Infant age (weeks) }\end{array}$ & & $19.8 \pm 1.0$ & $18-22$ \\
$\begin{array}{l}\text { Maternal African-American race } \\
\text { Less than 12 years of education }\end{array}$ & $62(82)$ & & $10.1-30.0$ \\
$\begin{array}{l}\text { Living in household poverty } \\
\text { Postpartum depression severity } \\
\text { Breastfeeding ( } \geq 80 \%)\end{array}$ & $62(82)$ & & \\
$\begin{array}{l}\text { Right handedness } \\
\text { Cannabis use }\end{array}$ & $6(8)$ & $2.97 \pm 3.94$ & $0-16$ \\
Observational measures & $68(90)$ & & \\
$\quad$ Maternal mental state talk & $24(32)$ & & \\
$\quad$ Positive involvement & & $2.89 \pm 0.85$ & $1-4$ \\
$\quad$ Negative insensitivity & & $\mathbf{0 . 0 9} \pm \mathbf{0 . 9 8}$ & $-2.61-1.50$ \\
Recognized own infant's cry after the scan & $68(89)$ & $-\mathbf{0 . 1 3} \pm \mathbf{0 . 8 3}$ & $-1.30-1.84$ \\
\hline
\end{tabular}

The bold scores reflect the principal components analysis strategy resulting in mean scores and SD close to 0 and 1 , respectively.

highly confident that the cry belonged to my infant, 5 for complete uncertainty about the infant's identity, 9 for highly confident that the cry belonged to another infant).

Imaging was performed on a 3.0 tesla (Siemens Trio) MRI scanner. Before BOLD fMRI scanning, T2-weighted and FLAIR MRI scans were acquired to rule out neuromorphological abnormalities. A high-resolution anatomical scan with voxels of $1 \mathrm{~mm}$ isotropic resolution MPRAGE sequence (160 slices; $256 \times 256$ acquisition matrix; TR, 2.3 s; TI, 900 ms; number of excitations, 1 ; flip angle, $9^{\circ}$ ) was obtained. After acquisition of a reference echoplanar imaging (EPI) to identify artifacts (i.e., ghosting) and to check for signal quality, BOLD functional images were acquired with a gradient-echo EPI sequence, covering 35 coronal slices ( $3 \mathrm{~mm}$ thick, $0 \mathrm{~mm}$ gap) encompassing the entire cerebrum and most of the cerebellum (TR, $2000 \mathrm{~ms}$; TE, $25 \mathrm{~ms}$; FOV, $24 \mathrm{~cm}$; matrix, $64 \times 64$ )

Data from 19 subjects were excluded for movement $>4 \mathrm{~mm}$, resulting in a final sample of 76 mothers with useable functional data. fMRI 
Table 2. Self-reports of own and other infant cry stimuli

\begin{tabular}{llllll}
\hline & \multicolumn{2}{l}{ Own infant cry (mean \pm SD) } & & \multicolumn{2}{l}{ Other infant cry (mean \pm SD) } \\
\cline { 2 - 3 } \cline { 5 - 6 } & Rating & Reaction time $(\mathrm{ms})$ & Response rate (\%) & Rating & Reaction time (ms) \\
\hline Felt distress & $3.01 \pm 0.54^{a}$ & $1198.39 \pm 368.42$ & $92.86 \pm 13.36$ & & $3.26 \pm 0.46^{b}$ \\
Urge to help & $3.41 \pm 0.60^{a}$ & $1098.96 \pm 362.42$ & $88.64 \pm 16.99$ & & $3.62 \pm 0.43^{b}$ \\
\hline
\end{tabular}

$a$ and $b$ indicate that the mean ratings were significantly different at $p<0.01$. Felt distress and urge to help were rated as 2 (low), 3 (medium), or 4 (high).

a

data were preprocessed and analyzed using statistical parametric mapping software (SPM8; Welcome Department of Imaging Neuroscience, University College London; www.fil.ion.ucl.ac.uk/spm). Data for each participant were realigned to the first volume to correct for head motion and unwarped to correct for static inhomogeneity of the magnetic field and movement by inhomogeneity interactions. Realigned and unwarped images were then coregistered with the participant's anatomical image. The anatomical image was normalized to the Montreal Neurological Institute (MNI) template using a nonlinear transformation and segmented into separate tissue types. BOLD images were then transformed to the same space via the parameters from the structural image segmentation, resampled to $2 \times 2 \times 2 \mathrm{~mm}^{3}$ voxels, despiked (implemented via Automated Functional Neuro-Imaging; http://afni.nimh.nih.gov/), and spatially smoothed with a $6 \mathrm{~mm}$ fullwidth at half-maximum.

Data analytic plan. First-level analysis of the neural data comprised a fixed-effects general linear model (GLM) of the BOLD response for each participant, with regressors indicating onset of own, other, and garbled infant cry stimuli (modeled as a block with a duration of $36 \mathrm{~s}$ ), respectively, and presentation of in-scanner questions and responses modeled as a block with a duration of $6 \mathrm{~s}$. Six head movement parameters from realignment were also included as regressors of no interest. A T contrast of own infant cry versus other infant cry was generated for each participant and was then carried into a second-level multi-participant random-effects wholebrain multiple linear regression analysis with the observed maternal behaviors (maternal mental state talk, positive involvement, and negative insensitivity) included as covariates. Within the second-level analysis, we report whole-brain results of the main effect contrast (own vs other infant cry) and the maternal behavior covariate effects. Significant results were reported at the threshold of voxel level $p<0.001$, and whole-brain FWE cluster corrected at $p<0.05$ unless specified otherwise. To further probe the relationship of maternal behavior with regions identified as significant in the whole-brain second-level analysis, we extracted the mean $\beta$ estimates from the functional masks based on significant clusters and examined their associations with observed mental state talk, positive involvement, and negative insensitivity.

Finally, we sought to verify the robustness of the main effects for own versus other contrast and the specificity of the associations between localized brain functional activity and observed maternal mental state talk identified in our group-level GLM. Therefore, we implemented a separate, second group-level GLM that, in addition to the regressors described above, included the own versus other difference in maternal cry perception and confidence in own infant identity to account for individual differences in perceptions of the auditory stimuli. We also controlled for the potentially confounding effects of maternal age, infant age, maternal race, years of education, poverty, postpartum depression severity, and cannabis use by simultaneously entering these variables to the model.

\section{Results}

\section{Participant characteristics}

Descriptive statistics for the sample are shown in Table 1. Mental state talk was associated moderately with the global ratings of positive maternal involvement $(r=0.47, p<0.001)$, consistent with previous work (Laranjo et al., 2008), but no relationships with negative insensitivity $(r=-0.07, p=0.56)$ or postpartum depression severity $(r=-0.05, p=0.63)$ were revealed. Three participants (4\%) reported probable depression on the EPDS. After the scan, most mothers $(89 \%)$ correctly recognized their own infant's cry. Participant behavioral ratings, reaction time, and rate of response to the infant cry stimuli during the scan are summarized in Table 2. Because "felt distress" and "urge to help" were correlated highly at $r=0.70(p<0.001)$, a mean score was used in the subsequent regression analysis.

Whole-brain analysis: increased neural activity to own versus other infant cry

Own infant cry, compared with other infant cry, was associated with increased BOLD responses in a cluster encompassing the RFIC (Fig. 2a,b; Table 3; peak [44, 34, -4$] ; Z=4.86$; voxel size, 286). In addition, several other regions, including the right inferior frontal gyrus in pars triangularis (BA45, dorsal to our activation cluster in RFIC), precuneus, right superior temporal sulcus (STS), right supplementary motor area (SMA), and middle inferior occipital cortex also showed stronger functional responses 
Table 3. Whole-brain analysis of neural activity to own > other infant cry and the neural correlates of maternal mental state talk with the functional activity in own versus other

\begin{tabular}{|c|c|c|c|c|c|c|}
\hline \multirow[b]{2}{*}{ Region } & \multirow[b]{2}{*}{ BA } & \multicolumn{3}{|c|}{ MNI coordinates } & \multirow[b]{2}{*}{ Z } & \multirow{2}{*}{$\begin{array}{l}\text { Voxel } \\
\text { size } k\end{array}$} \\
\hline & & $x$ & $y$ & $z$ & & \\
\hline \multicolumn{7}{|l|}{ Own versus other } \\
\hline RFIC & $47 / 13$ & 44 & 34 & -4 & 4.86 & $286^{* * *}$ \\
\hline $\begin{array}{l}\text { Right inferior frontal gyrus in pars } \\
\text { triangularis }\end{array}$ & 45 & 52 & 24 & 18 & 4 & 106 \\
\hline Right SMA & 6 & 4 & 16 & 64 & 4.12 & 70 \\
\hline Left precuneus & 7 & 0 & -60 & 32 & 3.52 & 50 \\
\hline Right STS & 21 & 66 & -36 & 0 & 3.59 & 38 \\
\hline Left middle occipital cortex & 18 & -28 & -96 & 0 & 3.65 & 37 \\
\hline $\begin{array}{l}\text { Regions whose activity in own versus other } \\
\text { was associated positively with } \\
\text { maternal mental state talk }\end{array}$ & & & & & & \\
\hline $\begin{array}{l}\text { Right thalamus, right amygdala, right } \\
\text { hippocampus, right parahippocam- } \\
\text { pus, right putamen, right pallidum, } \\
\text { and right insula }\end{array}$ & & 20 & -22 & 8 & 5.02 & $1585 * * *$ \\
\hline $\begin{array}{l}\text { Left thalamus, left hypothalamus, left } \\
\text { caudate, left mid-cingulum }\end{array}$ & & -26 & -18 & 24 & 4.29 & $794^{* * *}$ \\
\hline Left hippocampus, left amygdala & & -34 & -22 & -10 & 4.39 & $297^{* * *}$ \\
\hline Right ROC & 48 & 50 & 0 & 18 & 4.91 & $208^{* * *}$ \\
\hline Left frontal inferior operculum & 13 & -42 & 12 & 12 & 4.17 & $171^{* *}$ \\
\hline PAG & & 4 & -32 & -10 & 4.16 & $149^{* *}$ \\
\hline Right precuneus & & 26 & -56 & 20 & 4.15 & $111^{*}$ \\
\hline Right SMA & & 14 & -28 & 54 & 3.58 & 59 \\
\hline Left supplementary marginal area & 13 & -52 & -22 & 22 & 4.23 & 57 \\
\hline Left precentral gyrus & 6 & -34 & -10 & 52 & 3.55 & 55 \\
\hline $\begin{array}{l}\text { Left frontal inferior operculum/left } \\
\text { insula }\end{array}$ & $13 / 47$ & -24 & 18 & -10 & 3.93 & 44 \\
\hline Left precentral gyrus & & -38 & 0 & 26 & 3.8 & 40 \\
\hline Left insula & & -40 & -8 & -6 & 3.69 & 31 \\
\hline Left insula & & -30 & 26 & 12 & 3.49 & 31 \\
\hline
\end{tabular}

Regions shown at the threshold of voxel level $p<0.001$, voxel size $k>30$ are listed. ${ }^{*} p<0.05$, cluster level uncorrected. ${ }^{* *} p<0.05$, cluster level uncorrected, FWE-corrected marginal significance, $p$ values $<0.1$. ${ }^{* *} p<$ 0.05 , regions significant at cluster FWE-corrected are shown in bold.

during own versus other infant cry at a more liberal threshold (voxel-level $p<0.001$, cluster size $>30$; Table 3 ).

\section{Whole-brain analysis: associations between own versus other infant cry-related BOLD response and maternal caregiving behaviors}

When examining the associations between the functional activity of localized brain regions with observed caregiving, results from whole-brain multiple linear regression analysis showed that maternal mental state talk was associated positively with own versus other infant cry-related functional activity of four subcortical limbic and cortical clusters (Table 3 ). The first cluster was located in the right hemisphere, with peak activation in the right thalamus ([20,-22, 8]; $Z=5.02$; voxel size, 1585) extending along the amygdala, hippocampus, parahippocampus, putamen, and pallidum to the insula (Fig. 3; Table 3). The second (peak $[-26,-18,24] ; Z=4.29$; voxel size, 794) and third (peak $[-34,-22,-10] ; Z=4.39$; voxel size, 297) clusters were located in the symmetrical mirrored position relative to the first cluster in the left hemisphere, which together covered the left thalamus, amygdala, hippocampus, hypothalamus, and caudate. The fourth cluster was located in the right ROC (peak [50, 0, 18]; $Z=4.91$; voxel size, 208). The results also revealed several significant activations at a more liberal threshold of voxel-level $p<0.001$, cluster size $>30$. These included a cluster in the inferior frontal cortex positioned in the left hemisphere symmetrical to the RFIC, the cluster reported at the group level in the previous step with higher functional activity in own versus other contrast. We also identified significant clusters in the right precuneus, PAG, and bilateral premotor and motor areas (Table 3). In summary, the results revealed that higher levels of maternal mental state talk in face-to-face interaction were associated with higher functional activity in widespread cortical and subcortical regions that have been related to affective empathy, action mimicking, emotional and motivational processing, and social cognition.

In contrast, the results revealed no associations between own versus other infant cry-related functional activity and either observed positive involvement or negative insensitivity (even at the more liberal threshold of voxel-level $p<0.001$, cluster size $>30$ ), suggesting that the functional activity of these subcortical-cortical regions, induced by distressed infant stimuli, were relevant specifically for maternal mentalizing rather than other, more global, aspects of maternal caregiving behavior.

\section{ROI analysis: specific role of the RFIC}

Post hoc ROI analyses were conducted to probe the specific functional role of the RFIC, which was significantly more active to own versus other infant cry. When the association between the mean $\beta$ estimates for RFIC and observed maternal behaviors was examined, results showed that RFIC activity to own versus other infant cry was also specifically and positively associated with observed maternal mental state talk (Fig. $2 c ; r=0.26, p=0.02$ ) but was unrelated to observed positive involvement $(r=0.11, p=$ $0.34)$ or negative insensitivity $(r=-0.12, p=0.29)$.

\section{Accounting for maternal perceptions of cry stimuli and psychosocial covariates}

When the mean score of in-scanner felt distress and urge to help ratings was included in the models described above, the results remained unchanged, indicating that the functional involvement of the RFIC and subcortical regions during own versus other infant cry was not explained by the mothers' emotional or motivational response to distressing infant stimuli. The results were also unchanged when demographic, perceptual, and contextual characteristics of the sample (i.e., maternal age, infant age, maternal race, low education, postpartum depression severity, cannabis use, and identification of own infant) were included simultaneously as covariates.

\section{Discussion}

The current study tested hypotheses about the neural substrates of maternal mentalizing in a large sample of first-time mothers and extended previous research in several important directions. First, we found support for our hypotheses that there would be greater own versus other infant cry-related functional activity in the RFIC. Second, neural activity in a large, bilateral, subcortical network (e.g., thalamus, amygdala, and hippocampus) and right cortical regions (i.e., RFIC and ROC) was positively associated with independent observations of mothers' proclivity to use mental state talk while interacting with their infants even after controlling for a number of important perceptual and contextual covariates. These associations existed specifically for maternal mentalizing behavior and were not evident for more generic aspects of caregiving despite the moderate association between mental state talk and positive involvement. Thus, these results highlight the special functional importance of this RFIC-thalamic-limbic network in this circumscribed aspect of maternal caregiving. Our identified RFIC-thalamic-limbic net- 
work for maternal mentalizing overlaps with the general mentalizing neural network (Van Overwalle and Baetens, 2009; Fan et al., 2011; Carter and Huettel, 2013; Decety, 2015) in the RFIC, suggesting that there is a specific affective-perceptual empathy response that drives maternal mental state talk. Third, the large sample size provided sufficient statistical power to detect associations between mental state talk and functional activity in the hypothalamus and PAG. These two small anatomical structures have been identified in animal studies as having crucial functional importance for maternal behaviors (Numan and Woodside, 2010) but have been understudied in humans as a result of scanner resolution limitations (Swain and Lorberbaum, 2008).

The results derived from the wholebrain analysis did not reveal functional involvement of other key nodes from the general mentalizing network that have been identified in non-childbearing samples. These nodes include the dorsomedial prefrontal cortex and the temporoparietal junction whose important functional roles have been identified across various social contexts, including moral judgment (Young et al., 2010), altruism donation decisions (Saxe and Kanwisher, 2003; Hare et al., 2010; Carter et al., 2012) and collaboration (Le Bouc and Pessiglione, 2013). It is conceivable that these social contexts are more complex and abstract compared with an infant cry context and thus demand more cognitive perspective-taking and higher-order mentalizing than is needed in early maternal caregiving with a preverbal infant. Continued follow-up of the sample will be important to determine whether similar neural regions are related to maternal mentalizing capacity and maternal sensitivity as the child grows older and becomes a more complex interactional partner.

The size of the current sample permitted the inclusion of several important covariates, such as maternal perceptions of cry stimuli, recognition of own infant, sociodemographic variables, and postpartum depression severity. Because the results remained even after accounting for these perceptual and contextual variables, we can be reasonably confident that the regions we identified are reliable and valid components of the maternal network for this population of young, postpartum mothers and are not limited to specific subgroups characterized by infant cry perception or the contextual factors that were measured here. In particular, none of the results were explained by postpartum depression severity, suggesting that this maternal neural network (including the RFIC and thalamic-limbic regions) may function independently from the affective disordersensitive network. These results lend support to previous reports that maternal affective disorder does not necessarily undermine caregiving quality even among women at high social risk (Campbell et al., 2007; Kaitz et al., 2010; Parfitt et al., 2013). However, it should be noted that depression severity in this sample was low compared with other vulnerable and disadvantaged samples (Edge, 2007), and it is possible that this limited variability reduced statistical power to detect effects seen in other work (Moses-Kolko et al., 2014). Conversely, for many of these low socioeconomic, urban-living women, young motherhood may be a normative and adaptive life transition (Merrick, 1995; Geronimus, 2003) that is associated with postpartum well-being.

In addition to the identified cluster in the right RFIC, our results also revealed several regions (e.g., the precuneus, SMA, STS) that showed stronger neural responses to own versus other infant cry at a more liberal threshold. These results replicate previous reports of stronger neural responses in these regions to own infant cues (Swain et al., 2014), as well as specific empathic responses under arguably stressful circumstances of parenting a crying infant (Ho et al., 2014). We extend these findings by also demonstrating specific associations between own infant-related RFIC activity with maternal mental state talk but not with more global aspects of maternal caregiving. Additional investigation of distinct functional roles of these regions for various aspects of maternal behaviors, such as reflexive caregiving, planning, stress reactivity, emotion regulation, and the maintenance of sustained attention, is clearly warranted. For example, evidence supports the importance of the precuneus in the default mode network and its involvement in maternal function (Kim et al., 2011), selfother processing and theory of mind mental functions (Mars et al., 2012), and duties and responsibilities toward others (Johnson et al., 2006) even beyond one's immediate family (Swain et al., 2012). Future work is needed to replicate the results reported here but also to investigate the functional involvement of the precuneus for other well delineated components of early maternal behavior. Additional investigation is also needed into the potential roles of the inter-regional functional connectivity between the different key nodes of this network in other critical aspects of postpartum caregiving, such as stress reactivity, emotional regulation, and goal-directed action. 
In experimental laboratory research, it is not usually possible to match the acoustic properties of own and other infant cry stimuli or the different subjective effects they might have on the participants. In the current study, we elected to use the cry stimuli from an unfamiliar infant as a standard control stimulus that was presented to every subject. As described previously, the control cry was elicited in a laboratory setting by a pediatrician using an aversive stimulus (cloth over the face and pinched nose). In contrast, own infant cries were elicited in the home with preference for the least aversive stimulus to generate a cry. Consistent with the manner in which cry was elicited, the results showed that own infant cry was perceived as less distressing than this other infant cry stimulus. Nevertheless, the neural responses that were related to maternal behaviors were not influenced by varying perceptions of any of the cry stimuli. Such robustness of these effects further support the notion that these regions constitute an innate/inherent maternal network that are fundamental for maternal mentalizing regardless of the heterogeneity in the acoustic features of infant cry and psychological perceptions. It will be important to investigate neural components that are more sensitive to perceptions of infant temperament and acoustic features of the infant's cry.

Future work will make use of the rich longitudinal data gathered in the PGS to investigate the developmental origins of these neural and behavioral indices of maternal mentalizing. Important predictors may, for example, derive from mothers' own negative parenting experiences, mental health problems, trauma exposure, or interpersonal difficulties across childhood and adolescence. In preliminary analyses, we examined whether callous-unemotional (CU) behaviors assessed before conception predisposed mothers to show impairment in maternal mentalizing. The results showed that higher preconception CU behavior was associated significantly with lower (own vs other) infant cryrelated activity in the RFIC $(r=-0.34, p=0.004)$ and thalamus $(r=-0.35, p=0.003)$ and was associated marginally with reduced amygdala activity $(r=-0.23, p=0.057)$. In contrast, there was only a trend in the association between higher $\mathrm{CU}$ behavior and lower mental state talk $(r=-0.20, p<0.105)$. These results further validate the neural findings reported here and serve to highlight the importance of neural mechanism research that may be able to detect associations between early personality traits and later parenting behaviors more accurately than can be achieved with behavioral measures. Understanding these developmental influences will be critical to inform early detection and prevention of parenting deficits in vulnerable dyads.

The current study findings offer important insights into the neural substrates of maternal mentalizing that may have utility in informing individualized treatment for compromised parenting. For example, there are a number of extant behavioral/psychological treatment modalities aimed at addressing at-risk mother-infant dyads, including mentalizing-based approaches (Cooper et al., 2005; Sadler et al., 2013). Unfortunately, existing interventions are not uniformly effective, nor is treatment response always effectively maintained long term for psychological and biological (medication, neuromodulation) interventions. Neural mechanistic research offers the possibility of honing in on specific, individual-level neural signatures that can more clearly inform which treatment modality will have greatest efficacy for a particular individual. As such, the current study results may spur additional investigation of critical neural circuits underlying parenting dimensions that move the field closer to early detection of risks and personalization of treatment.

\section{References}

Abu-Akel A (2003) A neurobiological mapping of theory of mind. Brain Res Brain Res Rev 43:29-40. CrossRef Medline

Barrett J, Wonch KE, Gonzalez A, Ali N, Steiner M, Hall GB, Fleming AS (2012) Maternal affect and quality of parenting experiences are related to amygdala response to infant faces. Soc Neurosci 7:252-268. CrossRef Medline

Berlin LJ, Dodge KA, Reznick JS (2013) Examining pregnant women's hostile attributions about infants as a predictor of offspring maltreatment. JAMA Pediatr 167:549-553. CrossRef Medline

Campbell SB, Matestic P, von Stauffenberg C, Mohan R, Kirchner T (2007) Trajectories of maternal depressive symptoms, maternal sensitivity, and children's functioning at school entry. Dev Psychol 43:1202-1215. CrossRef Medline

Carr L, lacoboni M, Dubeau MC, Mazziotta JC, Lenzi GL (2005) Neural mechanisms of empathy in humans: a relay from neural systems for imitation to limbic areas. In: Social neuroscience: key readings, pp 143-152. New York: Psychology Press.

Carter RM, Huettel SA (2013) A nexus model of the temporal-parietal junction. Trends Cogn Sci 17:328-336. CrossRef Medline

Carter RM, Bowling DL, Reeck C, Huettel SA (2012) A distinct role of the temporal-parietal junction in predicting socially guided decisions. Science 337:109-111. CrossRef Medline

Cooper G, Hoffman K, Powell B, Marvin R (2005) The circle of security intervention: differential diagnosis and differential treatment. In: Enhancing early attachments: theory, research, intervention, and policy, pp 127-151. New York: Guilford.

Cox JL, Holden JM, Sagovsky R (1987) Detection of postnatal depression: development of the 10-item Edinburgh Postnatal Depression Scale. Br J Psychiatry 150:782-786. CrossRef Medline

Decety J (2015) The neural pathways, development and functions of empathy. Curr Opin Behav Sci 3:1-6. CrossRef

Doan SN, Wang Q (2010) Maternal discussions of mental states and behaviors: relations to emotion situation knowledge in European American and immigrant Chinese children. Child Dev 81:1490-1503. CrossRef Medline

Edge D (2007) Ethnicity, psychosocial risk, and perinatal depression-a comparative study among inner-city women in the United Kingdom. J Psychosom Res 63:291-295. CrossRef Medline

Fan Y, Duncan NW, de Greck M, Northoff G (2011) Is there a core neural network in empathy? An fMRI based quantitative meta-analysis. Neurosci Biobeh Rev 35:903-911. CrossRef Medline

Geronimus AT (2003) Damned if you do: culture, identity, privilege, and teenage childbearing in the United States. Soc Sci Med 57:881-893. CrossRef Medline

Gibson J, McKenzie-McHarg K, Shakespeare J, Price J, Gray R (2009) A systematic review of studies validating the Edinburgh Postnatal Depression Scale in antepartum and postpartum women. Acta Psychiat Scand 119:350-364. CrossRef Medline

Hare TA, Camerer CF, Knoepfle DT, Rangel A (2010) Value computations in ventral medial prefrontal cortex during charitable decision making incorporate input from regions involved in social cognition. J Neurosci 30:583-590. CrossRef Medline

Hipwell AE, Loeber R, Stouthamer-Loeber M, Keenan K, White HR, Kroneman L (2002) Characteristics of girls with early onset disruptive and antisocial behaviour. Crim Behav Ment Health 12:99-118. CrossRef Medline

Ho SS, Konrath S, Brown S, Swain JE (2014) Empathy and stress related neural responses in maternal decision making. Front Neurosci 8:152. CrossRef Medline

Iacoboni M, Dapretto M (2006) The mirror neuron system and the consequences of its dysfunction. Nat Rev Neurosci 7:942-951. CrossRef Medline

Johnson MK, Raye CL, Mitchell KJ, Touryan SR, Greene EJ, Nolen-Hoeksema S (2006) Dissociating medial frontal and posterior cingulate activity during selfreflection. Soc Cogn Affect Neurosci 1:56-64. CrossRef Medline

Kaitz M, Maytal HR, Devor N, Bergman L, Mankuta D (2010) Maternal anxiety, mother-infant interactions, and infants' response to challenge. Infant Behav Dev 33:136-148. CrossRef Medline

Keenan K, Hipwell A, Chung T, Stepp S, Stouthamer-Loeber M, Loeber R, McTigue K (2010) The Pittsburgh Girls Study: overview and initial findings. J Clin Child Adolesc Psychol 39:506-521. CrossRef Medline

Kim P, Feldman R, Mayes LC, Eicher V, Thompson N, Leckman JF, Swain JE (2011) Breastfeeding, brain activation to own infant cry, and maternal sensitivity. J Child Psychol Psychiatry 52:907-915. CrossRef Medline

Laranjo J, Bernier A, Meins E (2008) Associations between maternal mind- 
mindedness and infant attachment security: investigating the mediating role of maternal sensitivity. Infant Behav Dev 31:688-695. CrossRef Medline

Le Bouc R, Pessiglione M (2013) Imaging social motivation: distinct brain mechanisms drive effort production during collaboration versus competition. J Neurosci 33:15894-15902. CrossRef Medline

Lorber MF, Egeland B (2009) Infancy parenting and externalizing psychopathology from childhood through adulthood: developmental trends. Dev Psychol 45:909-912. CrossRef Medline

Mammen O, Kolko D, Pilkonis P (2003) Parental cognitions and satisfaction: relationship to aggressive parental behavior in child physical abuse. Child Maltreatment 8:288-301. CrossRef Medline

Mars RB, Sallet J, Schüffelgen U, Jbabdi S, Toni I, Rushworth MF (2012) Connectivity-based subdivisions of the human right "temporoparietal junction area": evidence for different areas participating in different cortical networks. Cereb Cortex 22:1894-1903. CrossRef Medline

Meins E, Fernyhough C (1999) Linguistic acquisitional style and mentalising development: the role of maternal mind-mindedness. Cognit Dev 14:363-380. CrossRef

Meins E, Fernyhough C, Wainwright R, Clark-Carter D, Das Gupta M, Fradley E, Tuckey M (2003) Pathways to understanding mind: construct validity and predictive validity of maternal mind-mindedness. Child Dev 74:1194-1211. CrossRef Medline

Meins E, Fernyhough C, de Rosnay M, Arnott B, Leekam SR, Turner M (2012) Mind-mindedness as a multidimensional construct: appropriate and nonattuned mind-related comments independently predict infantmother attachment in a socially diverse sample. Infancy 17:393-415. CrossRef

Menkes J, Sarnat H, Moser F (2000) Neurologic examination of the child and infant. In: Child neurology, Ed 6 (Menkes J, Sarnat H, eds), pp 1-32. Philadelphia: Lippincott Williams and Wilkins.

Merrick EN (1995) Adolescent childbearing as career "choice": perspective from an ecological context. J Counsel Dev 73:288-295. CrossRef

Molenberghs P, Cunnington R, Mattingley JB (2012) Brain regions with mirror properties: a meta-analysis of 125 human fMRI studies. Neurosci Biobehav Rev 36:341-349. CrossRef Medline

Moses-Kolko EL, Horner MS, Phillips ML, Hipwell AE, Swain JE (2014) In search of neural endophenotypes of postpartum psychopathology and disrupted maternal caregiving. J Neuroendocrinol 26:665-684. CrossRef Medline

Musser ED, Kaiser-Laurent H, Ablow JC (2012) The neural correlates of maternal sensitivity: an fMRI study. Dev Cogn Neurosci 2:428-436. CrossRef Medline

Numan M, Woodside B (2010) Maternity: Neural mechanisms, motivational processes, and physiological adaptations. Behav Neurosci 124: 715-741. CrossRef Medline

Oldfield RC (1971) The assessment and analysis of handedness: the Edinburgh inventory. Neuropsychologia 9:97-113. CrossRef Medline

Parfitt Y, Pike A, Ayers S (2013) The impact of parents' mental health on parent-baby interaction: a prospective study. Infant Behav Dev 36: 599-608. CrossRef Medline

Rizzolatti G, Fabbri-Destro M (2008) The mirror system and its role in social cognition. Curr Opin Neurobiol 18:179-184. CrossRef Medline

Sadler LS, Slade A, Close N, Webb DL, Simpson T, Fennie K, Mayes LC
(2013) Minding the baby: enhancing reflectiveness to improve early health and relationship outcomes in an interdisciplinary home-visiting program. Infant Ment Health J 34:391-405. CrossRef Medline

Sander K, Frome Y, Scheich H (2007) FMRI activations of amygdala, cingulate cortex, and auditory cortex by infant laughing and crying. Hum Brain Mapp 28:1007-1022. CrossRef Medline

Saxe R, Kanwisher N (2003) People thinking about thinking people. The role of the temporo-parietal junction in "theory of mind." Neuroimage 19:1835-1842. CrossRef

Sharp C, Fonagy P (2008) The parent's capacity to treat the child as a psychological agent: constructs, measures and implications for developmental psychopathology. Soc Dev 17:737-754. CrossRef

Shaw DS, Winslow EB, Owens EB, Vondra JI, Cohn JF, Bell RQ (1998) The development of early externalizing problems among children from lowincome families: a transformational perspective. J Abnorm Child Psychol 26:95-107. CrossRef Medline

Soltis J (2004) The signal functions of early infant crying. Behav Brain Sci 27:443-458; discussion 459-490. Medline

Strathearn L, Kim S (2013) Mothers' amygdala response to positive or negative infant affect is modulated by personal relevance. Front Neurosci 7:176. CrossRef Medline

Swain JE, Lorberbaum JF (2008) Imaging the human parental brain. In: Neurobiology of the parental brain (Bridges R, ed.), pp 83-100. New York: Academic. CrossRef

Swain JE, Mayes LC, Leckman JF (2004) The development of parent-infant attachment through dynamic and interactive signalling loops of care and cry. Behav Brain Sci 27:472-473. CrossRef

Swain JE, Lorberbaum JP, Kose S, Strathearn L (2007) Brain basis of early parent-infant interactions: psychology, physiology, and in vivo functional neuroimaging studies. J Child Psychol Psychiatry 48:262-287. CrossRef Medline

Swain JE, Tasgin E, Mayes LC, Feldman R, Constable RT, Leckman JF (2008) Maternal brain response to own baby-cry is affected by cesarean section delivery. J Child Psychol Psychiatry 49:1042-1052. CrossRef Medline

Swain JE, Konrath S, Brown SL, Finegood ED, Akce LB, Dayton CJ, Ho S (2012) Parenting and beyond: common neurocircuits underlying parental and altruistic caregiving. Parent Sci Practice 12:115-123. CrossRef

Swain JE, Kim P, Spicer J, Ho SS, Dayton CJ, Elmadih A, Abel KM (2014) Approaching the biology of human parental attachment: Brain imaging, oxytocin and coordinated assessments of mothers and fathers. Brain Res 1580:78-101. CrossRef Medline

Taumoepeau M, Ruffman T (2008) Stepping stones to others' minds: Maternal talk relates to child mental state language and emotion understanding at 15, 24, and 33 months. Child Dev 79:284-302. CrossRef Medline

Tronick EZ, Olson K, Rosenberg R, Bohne L, Lu J, Lester BM (2004) Normative neurobehavioral performance of healthy infants on the neonatal intensive care unit network neurobehavioral scale. Pediatrics 113:676-678. Medline

Van Overwalle F, Baetens K (2009) Understanding others' actions and goals by mirror and mentalizing systems: a meta-analysis. Neuroimage 48: 564-584. CrossRef Medline

Young L, Camprodon JA, Hauser M, Pascual-Leone A, Saxe R (2010) Disruption of the right temporoparietal junction with transcranial magnetic stimulation reduces the role of beliefs in moral judgments. Proc Natl Acad Sci U S A 107:6753-6758. CrossRef Medline 